\title{
Survey of treatment of primary breast cancer in Great Britain
}

\author{
JEAN-CLAUDE GAZET, RICHARD M RAINSBURY, HUBERT T FORD, \\ TREVOR J POWLES, R CHARLES COOMBES
}

\begin{abstract}
A postal survey of current management of breast cancer among surgeons in Great Britain was carried out. The results showed that there is no consensus among surgeons about the treatment of primary breast cancer. Many different types of primary surgery are practised, and patterns of referral for postoperative radiotherapy vary widely. Adjuvant systemic treatment is given often by some surgeons and not at all by others. Few patients are entered into controlled randomised trials.
\end{abstract}

\section{Introduction}

During the past decade various clinical trials have indicated the need for reappraisal of the best treatment for primary breast cancer. These trials have related to the type of surgery and use of radiotherapy and to the use of adjuvant systemic treatment. Randomised studies have indicated that survival is not radically influenced by the type of local treatment for primary breast cancer, ${ }^{1}$ although prevention of local recurrence depends on adequate primary surgery or radiotherapy, or both. ${ }^{2}$ In addition, many patients have now been treated by conservative surgery and radiotherapy; this has shown that survival is similar to that in

Royal Marsden Hospital, Sutton, Surrey SM2 5PX

JEAN-CLAUDE GAZET, MS, FRCS, consultant surgeon RICHARD M RAINSBURY, MS, FRCS, senior registrar

HUBERT T FORD, FRCR, consultant radiotherapist

TREVOR J POWLES, PHD, FRCP, consultant physician

Ludwig Institute for Cancer Research, Sutton, Surrey SM2 5PX

R CHARLES COOMBES, MD, MRCP, senior clinical scientist and honorary consultant physician

Correspondence and requests for reprints to: Mr Jean-Claude Gazet. patients treated by mastectomy.$^{34} \mathrm{With}$ regard to treatment aimed at improving the survival of patients with primary breast cancer, studies have indicated that systemic combination chemotherapy can improve survival in some patients, particularly those who are

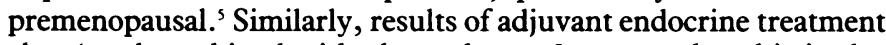
alone $^{6}$ and combined with chemotherapy ${ }^{7}$ suggest that this is also effective in delaying recurrence and may improve overall survival.

We were interested to see whether these results had influenced surgeons' practices and therefore undertook a survey of all consultant surgeons in Great Britain, requesting information about their policies for treatment for primary breast cancer and their participation in clinical trials in the United Kingdom.

\section{Methods}

In September 1983 a questionnaire was sent by post to all 766 consultant surgeons who were fellows of the Association of Surgeons of Great Britain and Ireland. This requested information on the following points: (1) the number of new patients with primary operable breast cancer seen yearly; (2) the proportions of patients treated by mastectomy and by conservative surgery (wide excision, tylectomy (by "lumpectomy"), or biopsy); (3) the type of mastectomy carried out, and which of the patients who were treated by mastectomy also received postoperative radiotherapy; (4) the type of conservative surgery carried out in patients so treated, and which of them received postoperative radiotherapy; (5) the proportion of patients who received adjuvant systemic treatment immediately after primary surgery; and (6) the proportion of patients who received adjuvant treatment and systemic endocrine treatment or chemotherapy, and the proportion entered into clinical trials.

\section{Results}

Of the 766 questionnaires sent out, 537 were completed; 229 surgeons did not reply. Eighty three surgeons stated that they did not see patients with breast disease. The results of this survey are based on the 454 surgeons who had an interest in or treated breast diseases. 


\section{NUMBER OF PATIENTS SEEN}

The 454 surgeons indicated that they saw roughly 17000 new patients a year between them. Table I shows that only 110 surgeons saw more than 50 new cases a year. Surgical practice, including referral for radiotherapy and systemic chemotherapy, did not appear to be affected by the number of cases seen.

\section{SURGICAL TREATMENT}

Mastectomy was considered to be the treatment of choice by most surgeons. The most common form of mastectomy was total mastectomy (whole breast with or without dissection of the axillary gland), performed by 272 surgeons, followed by modified radical mastectomy (Patey mastectomy), performed by 123 . The least favoured operation was radical mastectomy (Halstead mastectomy). Only six surgeons stated that they never performed mastectomy. In contrast, 47 surgeons never performed any type of conservative surgery (table II).
Adjuvant endocrine treatment was generally more popular with surgeons than adjuvant chemotherapy (ratio $2 \cdot 5: 1$ ). Of the surgeons using adjuvant treatment of any description, 93 never used adjuvant chemotherapy but only endocrine treatment, and 57 never used endocrine treatment but only adjuvant chemotherapy.

Roughly one third of the surgeons who replied to the question on entry into trials stated that most of their patients were entered into adjuvant studies of some description. A similar proportion said that it was their practice never to enter patients into adjuvant studies. Surgeons who saw more than 100 patients a year did not necessarily enter more patients into clinical trials (table I).

\section{Discussion}

The most important conclusion of this survey was that there is no consensus of opinion on how primary breast cancer should be managed, as practically every permutation of surgery, radio-

TABLE I-Surgical practice and number of patients seen each year

\begin{tabular}{llccc}
\hline & \multicolumn{3}{c}{ No of new patients seen a year } \\
\cline { 2 - 4 } & $1-25$ & $26-50$ & $51-100$ & $>100$ \\
\hline No of surgeons & 172 & 172 & 88 & 22 \\
No (\%) who: & $120(69 \cdot 8)$ & $111(64 \cdot 5)$ & $62(70 \cdot 5)$ & $11(52 \cdot 3)$ \\
Treat over three quarters of patients by mastectomy & $10(5 \cdot 8)$ & $17(9 \cdot 9)$ & $9(10 \cdot 2)$ & $5(23.8)$ \\
Advise radiotherapy after mastectomy for patients with non-diseased lymph nodes & $9(5 \cdot 2)$ & $11(6 \cdot 4)$ & $9(10 \cdot 2)$ & $3(14 \cdot 3)$ \\
Do not give adiuvant treatment & $43(25)$ & $42(24 \cdot 4)$ & $25(28 \cdot 4)$ & $10(42 \cdot 9)$ \\
Enter over half of patients into trials of systemic treatment & $19(11)$ & $18(10 \cdot 5)$ & $11(12 \cdot 5)$ & $8(33.3)$ \\
Give over half of patients adjuvant chemotherapy & $53(30 \cdot 8)$ & $57(33 \cdot 1)$ & $34(38 \cdot 6)$ & $8(33 \cdot 3)$
\end{tabular}

TABLE II-Surgical treatment of breast cancer

\begin{tabular}{lcc}
\hline \multirow{2}{*}{$\%$ of patients treated by surgeon } & \multicolumn{2}{c}{ No $(\%)$ of surgeons treating breast cancer: } \\
\cline { 2 - 3 } & Mastectomy & Conservative surgery \\
\hline $76-100$ & $305(67 \cdot 1)$ & $45(9 \cdot 7)$ \\
$51-75$ & $77(17)$ & $37(8) 2)$ \\
$26-50$ & $27(6)$ & $63(13 \cdot 9)$ \\
$1-25$ & $39(8 \cdot 6)$ & $262(57 \cdot 8)$ \\
None & $6(1 \cdot 3)$ & $47(10 \cdot 4)$ \\
\hline Total & 454 & 454 \\
\hline
\end{tabular}

When conservative surgery was performed $317(70 \%)$ surgeons performed wide local excision, 73 performed tylectomy (local excision or lumpectomy), and 41 used a Tru-Cut or drill biopsy as a preliminary procedure to radiation treatment. Only 65 surgeons carrying out any form of conservative surgery performed biopsies on the ipsilateral axillary glands at the same time. Over $70 \%$ of patients underwent some form of mastectomy and less than $24 \%$ some form of operation aimed at conserving the breast.

\section{RADIOTHERAPY}

Four hundred and twenty two surgeons said that it was their practice to obtain an opinion on postoperative radiotherapy for some of their patients after mastectomy. Many surgeons (250) said that they would consider referring only patients who had one or more diseased nodes for radiotherapy; 100 said that they would refer only patients who had four or more diseased nodes; and 41 recommended referral for radiotherapy even for patients treated by mastectomy whose nodes were not affected.

Over half of the surgeons (250) said that they would not advise postoperative radiotherapy for their patients with $T_{3}$ or $T_{4}$ tumours

Forty one surgeons never advised patients to undergo radiotherapy after conservative surgery, and only half of all the surgeons stated that radiotherapy was given to all patients treated in this way.

\section{ADJUVANT SYSTEMIC TREATMENT}

Table III shows details of adjuvant systemic treatment. Thirty two surgeons stated that none of their patients received adjuvant treatment of any description; 305 advised it for a few of their patients; and only 99 stated that most of their patients received adjuvant treatment. therapy, and systemic treatment is used. Surgeons do not appear to follow results of trials but use their own treatment. Furthermore, only one out of four surgeons claims to see more than 50 patients with breast cancer a year, presumably in some sort of breast clinic, which suggests that most patients with breast cancer in the United Kingdom are still seen in general surgical clinics. So few surgeons reported seeing large numbers of patients with breast cancer, however, that it is difficult to draw firm conclusions about their practice, but they seemed to treat their patients in a fashion similar to that of surgeons who see the disease less often.

IABL.F. III-Adjuvant systemic treatment of breast cancer

\begin{tabular}{lcccc}
\hline \multirow{4}{*}{$\begin{array}{l}\text { No of patients } \\
\text { treated by } \\
\text { surgeon }\end{array}$} & $\begin{array}{c}\text { Giving any form } \\
\text { of adjuvant } \\
\text { treatment }\end{array}$ & $\begin{array}{c}\text { Giving adjuvant } \\
\text { endocrine } \\
\text { treatment }\end{array}$ & $\begin{array}{c}\text { Giving } \\
\text { adjuvant } \\
\text { chemotherapy }\end{array}$ & $\begin{array}{c}\text { Entering } \\
\text { patients } \\
\text { into trials }\end{array}$ \\
\hline $76-100$ & $46(10 \cdot 6)$ & $106(31 \cdot 9)$ & $33(11 \cdot 3)$ & $104(32 \cdot 5)$ \\
$51-75$ & $53(12 \cdot 2)$ & $45(13 \cdot 6)$ & $22(7 \cdot 5)$ & $15.7 \cdot 7)$ \\
$26-50$ & $58(13 \cdot 3)$ & $35(10 \cdot 5)$ & $25(8 \cdot 6)$ & $10(3 \cdot 1)$ \\
$1-25$ & $247(56 \cdot 7)$ & $99(29 \cdot 8)$ & $144(49 \cdot 3)$ & $87(27 \cdot 2)$ \\
None & $32(7 \cdot 3)$ & $47(14 \cdot 2)$ & $68(23 \cdot 3)$ & $104(32 \cdot 5)$ \\
\hline Total* & 436 & 332 & 292 & 320 \\
\hline
\end{tabular}

*Some surgeons did not answer this question.

Mastectomy is apparently still the most common surgical procedure for breast cancer in this country, as $84 \%$ of surgeons treated most of their patients with breast cancer by mastectomy. This trend for radical local treatment was also reflected in the pattern of referral for local radiotherapy as many surgeons regarded radiotherapy as mandatory in patients treated by mastectomy or conservative surgery. It was surprising, however, that so many patients received radiotherapy after mastectomy, particularly in view of the lack of effect on survival that had been shown previously. Conversely, some surgeons did not recommend radiotherapy in patients with large tumours or those who had been treated by conservative surgery.

Only $16 \%$ of surgeons who practised conservative surgery took biopsy specimens of the axilla at the same time. It seems that 
surgeons are reluctant to stage the axilla during conservative surgery. Although adjuvant systemic treatment appears to be given to a fairly large proportion of patients, this is usually endocrine treatment. Chemotherapy is given less often, perhaps because of the difficulties in administering it in a general surgical clinic.

Finally, we were disappointed to find that so few patients were included in clinical trials-for example, only $37 \%$ of surgeons who treated more than half their patients with adjuvant systemic treatment did so as part of a clinical trial.

With the prevalence and diversity of breast cancer and the complexities of the many options for treatment perhaps the time has come to encourage treatment by specialised breast units. This would permit conformity of management of the disease and facilitate research into new modes of treatment throughout the country.

We thank the Breast Cancer Research Trust for supporting this survey,
Lynne Wilcox for collating the data, and Janice Davidson for supervising the computer documentation.

\section{References}

1 Veronesi U, Saccozzi R, Del Vecchio $M$, et al. Comparing radical mastectomy with quad rantectomy, axillary dissection, and radiotherapy in patients with small cancers of the breast. $N$ Engl f Med 1981;305:6-1

2 Cancer Research Campaign. Management of early cancer of the breast. Report on an international multicentre trial supported by the Cancer Research Campaign. Br Med f 1976; ;: 1035-8.

3 Calle R, Pilleron JP, Schlienger P, Vilcoq JR. Conservative management of operable breast cancer. Cancer 1978;42:2045-53.

4 Pierquin B, Owen R, Maylin C, et al. Radical radiation therapy of breast cancer. Int $\mathcal{J}$ Radiat Oncol Biol Phys 1980;6:17-24.

5 Bonadonna G, Brusamolino E, Valagussa P, et al. Combination chemotherapy as an adjuvan treatment in operable breast cancer. $N$ Engl f Med 1976;294:405-10.

6 Baum M, Brinkley DM, Dossett JA, et al. Improved survival amongst patients treated with adjuvant tamoxifen after mastectomy for early breast cancer. Lancet 1983;ii:450.

7 Fisher B, Newman C, Brown A, et al. Treatment of primary breast cancer with chemotherapy and tamoxifen. N Engl f Med 1981;305:1-6.

(Accepted 6 March 1985

\title{
Validation of a self administered questionnaire to elicit gastrointestinal symptoms
}

\author{
E M CHISHOLM, F T DE DOMBAL, G R GILES
}

\begin{abstract}
Self administered questionnaires are becoming popular investigative tools in medical research, yet few reports state the extent of methods used to validate these questionnaires before their general use. A pilot study was therefore carried out to validate a 41 item questionnaire for use in a population screening study for gastrointestinal disease.

Participants in the study comprised 69 population controls, 40 patients with benign disease, and 35 patients with gastrointestinal cancer. Acceptability, ease of completion, reliability, and reproducibility of the questionnaire were all assessed. Only one subject refused to complete the questionnaire. Ninety six per cent of the questions were completed by each subject and only one response in $\mathbf{1 4 4 0}$ was altered in the reproducibility study. The questionnaire disclosed symptoms similar to those elicited by a clinician and highlighted unreported gastrointestinal symptoms in the control group. Three questions were found to be unreliable and were altered before the questionnaire was put into general use.

It is concluded that a pilot study to validate a new questionnaire is simple to perform and necessary to identify unreliable questions.
\end{abstract}

\section{Introduction}

Self adminstered health questionnaires have been used as an adjunct to medical history taking for many years, ${ }^{1}$ but more recently questionnaires have been seen as investigative tools to identify risk groups for cardiac disease,,$^{2}$ colorectal neoplasia, ${ }^{3+}$ and upper

University Department of Surgery, St James's University Hospital, Leeds LS9 7TF E M CHISHOLM, BSC, FRCS research fellow

F T DE DOMBAL, MD, FRCS, reader in clinical information sciences

G R GILES, MD, FRCS, professor of surgery

Correspondence to: Professor G R Giles. gastrointestinal disease. ${ }^{5}$ Few questionnaires, however, have been subjected to critical statistical analysis to determine their validity before being used clinically. ${ }^{6}$ To be valid a questionnaire needs to meet five criteria: $(a)$ to be acceptable to the population under study; (b) to be easily completed; $(c)$ to be consistent-that is, to elicit responses similar to those gained in a conventional doctor-patient interview; $(d)$ to be reproducible when administered on two separate occasions; $(e)$ to be of value or use when complete.

We report the steps taken to validate a questionnaire to elicit gastrointestinal symptoms in a screening programme for bowel cancer.

\section{Questionnaire}

The questionnaire contained 41 questions. Eighteen were specifically related to gastrointestinal symptoms - oesophagus (3), stomach (3), bowel habit (8), weight and appetite (4)-and the remainder covered epidemiological data (4), previous medical history (6), family history (2), and a general systems inquiry (11)-respiratory system, genitourinary system, and drug usage. The questions were closed in nature and it was possible to omit five responses if negative answers were given to the preceding question. To answer a question a tick was placed in the appropriate yes or no box.

\section{Patients and methods}

A total of 144 subjects were enrolled and were divided into three groups: 69 "normal" subjects who were not attending hospital; 40 patients with proved benign gastrointestinal conditions; and 35 patients with proved gastrointestinal cancer. All 144 subjects were required to complete the form unaided in order to assess the acceptability and feasibility of completing the questionnaire. A test-retest system was used to assess the reproducibility of the responses, 20 subjects being required to complete a second questionnaire after a two week interval.

Twenty three patients with symptoms referred to hospital by their general practitioner completed a questionnaire before being interviewed in the routine manner by a consultant. To determine the consistency of the responses on the patient's questionnaire the clinician then completed an identical questionnaire on the basis of the interview and without reference to the patient's form. The two forms were then compared using kappa statistics. 